Review

\title{
Prevention of Hearing Loss by Alteration of the Systemic Immune System
}

Iwai $\mathrm{H}^{1^{*}}$, Inaba $\mathrm{M}^{2}$.

${ }^{1}$ Department of Otolaryngology, Head and Neck Surgery, ${ }^{2}$ First Department of Medicine, Kansai Medical University, Osaka, Japan.

*Correspondence: iwai@hirakata.kmu.ac.jp

${ }^{1}$ Department of Otolaryngology, Head and Neck Surgery, Kansai Medical University, Hirakata, Osaka, Japan.

\begin{abstract}
Although congenital sensorineural hearing loss (SHL) in the bilateral cochleae mainly results from genetic abnormalities, chronic SHL progressing in later life is often influenced by systemic immune disturbances, including autoimmunity, chronic inflammation, and immunosenescence.

We have investigated the relationship between the inner ear and systemic immunity and reviewed the possibilities to prevent SHL, including autoimmune SHL and age-related SHL. We also demonstrated two lymphocyte populations, interleukin 1 receptor type II (IL-1R2)-positive T cells (T1R2) and naturally occurring regulatory $\mathrm{T}$ cells (nTregs) in $\mathrm{CD} 4^{+} \mathrm{T}$ cells, which increase with aging, suppress host immune function and promote organ degeneration. Alterations in systemic immunity by fewer microbial antigen challenges in the living environment, elimination of immune suppressive lymphocytes, or immune rejuvenation with a reconstituted thymus may contribute not only to renew the cochlear function in SHL, but also to extend the healthy life of functional organs in a vigorous and youthful body, one of humanity's greatest dreams.
\end{abstract}

Key words: autoimmune sensorineural hearing loss; age-related sensorineural hearing loss; inflammation, immune senescence; interleukin 1 receptor type II -positive T cells; naturally occurring regulatory $\mathrm{T}$ cells; immune rejuvenation; thymus.

\section{Background}

Although Sjögren's syndrome and Behcet's disease typically show oral lesions, it is well known that they are systemic symptoms beyond otolaryngology, and the head and neck area. Eosinophilic otitis media (EOM) and otitis media with antineutrophil cytoplasmic antibody (ANCA) show not only otitis media, but also a deterioration in systemic immunity $[1,2]$.

Sensorineural hearing loss (SHL) in the inner ear, as opposed to conductive hearing loss in the middle ear including the ear drum, is also a partial manifestation in type 2 diabetes[3], cardiovascular disease, systematic lupus erythematosus (SLE)[4], and granulomatosis with 
polyangiitis (GPA)[5] . Age-related SHL, also known as presbycusis, connected with systemic aging develops due to mitochondrial DNA damage in the cochlea following oxidative stress [6] and shows a delay in progression with exercise or caloric restriction [7-9]. One of the authors previously demonstrated that food restriction upregulates interleukin 2 receptor (IL-2R) on T lymphocytes and activates cellular immunity in mice [10]. Thus, cochlear function and pathology are affected by, or coordinated with, the systemic environment including the immune system. We have also studied preventive treatments for progressive bilateral SHL caused by disturbances in systemic immunity with autoimmune diseases or aging, but not caused by genetic abnormalities or acoustic trauma [11$18]$.

In this review, we have chosen to focus on cochlear function and pathology related to the systemic immune system and the possibility of controlling the development of SHL.

\section{Treatment of autoimmune SHL with allogeneic bone marrow transplantation}

The transplantation of hemopoietic stem cells provides an opportunity to provoke a "reset" of the immune system in patients with autoimmune diseases [19] and has been utilized in the treatment of a whole spectrum of severe autoimmune diseases refractory to conventional therapy [20,21].

The MRL/Mp-lpr/lpr (MRL/lpr) mouse strain, a murine model of autoimmune SHL and SLE, shows progressive SHL by 20 weeks of age [22,23] and lupus nephritis at 12-16 weeks [24]. This strain has reduced Fas messenger RNA (mRNA) production and decreased negative selection of self-reactive T cells, followed by the production of autoantibodies (anti-single-stranded DNA [ssDNA] antibody, rheumatoid factor $[R F]$, etc.) by B cells or by the deposition of an $\operatorname{IgG}$ (autoantibody)-containing immune complex in the lesions of the stria vascularis [22,23], as well as the basement membranes of the glomeruli [25] This vascularis is known to function in the maintenance of the blood-labyrinth barrier and auditory functions [26], and has been identified as the most likely site of disease-causing autoimmune SHL [25,27].

We performed allogeneic bone marrow transplantation (BMT) in which MRL/lpr recipient mice received bone marrow cells from young C57BL/6 mice which are non-autoimmune prone and show slow manifestation of presbycusis $[12,13]$. The BMT procedures consist of systemic irradiation with 9-10 Gy to delete immunocompetent cells, including bone marrow cells, in recipients and then inoculating bone marrow cells from C57BL/6 donor mice.

The results have indicated that BMT can be used to treat SHL as well as SLE; cochlear pathology, serum autoantibodies and lupus nephritis were all ameliorated. Therefore, it is conceivable that the autoimmune SHL in the MRL/lpr mice results not from defects in the cochlea, including the stria vascularis, but from defects in the systemic immune system constituted by bone marrow cells [13]. BMT could therefore provide a curative effect on inner ear autoimmune dysfunction associated with systemic autoimmune diseases including not only SLE, but also RA [28-30], ulcerative colitis [31,32], 
relapsing polychondritis [33], steroid-responsive sensorineural hearing loss [34].

\section{Retardation of age-related SHL by restraint of chronic inflammation due to bacterial infection}

The causes of chronic bilateral SHL mainly include genetic factors, noise exposure, ototoxic drugs, oxygenic stress, and excessive intake of calorie $[7,8,35,36]$. On the other hand, these factors alone cannot explain progression of age-related SHL, which is rapidly increasing in incidence, affecting about half of the population over 75 years old $[37,38]$ and that to date has been an incurable disease.

Recent research in gerontology has shown that inflammaging, a state of chronic systematic inflammation associated with age, is a consequence of immunosenescence, the aging of the immune system, that contributes to the aging process and the development of age-related disabilities and diseases including age-related SHL [39,40]. Local inner ear immunity is part of the overall systemic response and can induce cochlear degeneration and SHL [16,41-43]. Type II diabetes and cardiovascular disease associated with inflammaging have been identified as being linked to agerelated SHL severity [44]. Verschuur et al. [38] indicated that chronic inflammation represented by the white blood cell count was strongly associated with a worsening of age-related SHL among community-dwelling adults aged over 75 years.

A senescent immune system is characterized by continuous reshaping and shrinkage of the immune repertoire by persistent antigenic challenges. These changes lead to a poor response to newly encountered microbial antigens, as well as to a shift in the immune system towards an inflammatory or autoimmune profile [39]. Laboratory animals show longer lifespans in immunologically clean environments because of the absence of immune stress, which is mainly due to chronic infections due to pathogenic invaders [45]. The time onset of these age-related diseases and the mean survival time also depend on the environment, which can consist of specific pathogen-free (SPF) conditions or conventional (CV) conditions [46].

Therefore, we examined audiological, pathological and immunological differences between breeding conditions of SPF and CV in the senescence-associated mouse type 1 (SAMP1), a murine inbred strain with a genetic background of AKR mice [47,48], which shows the early occurrence of thyme involution and accelerated dysfunction of immunocompetent cells, particularly $\mathrm{T}$ cells, followed by acceleration of age-related SHL with the degeneration of spiral ganglion (SG) neurons in the cochlea $[44,47]$. The results indicated the retardation of age-related SHL and degeneration of SG neurons, as well as prevention of immunosenescence, in the SPF mice [15].

These findings raise the question as to why systemic immune functions affect cochlear function. One reason is oxygenic stress produced in the body as inflammaging, with immune senescence influencing the inner ear through blood flow [48]. Another reason is systemic immunity itself: We have previously demonstrated that $\mathrm{T}$ cells in the systemic circulation infiltrate the inner ear and proliferate locally as a consequence of the immune response in a mouse model of graft-versus-host 
disease using BALB/c and C57BL/6 mice [11]. Subramanian et al. [49] demonstrated that activated $\mathrm{T}$ cells enter the central nervous system and modulate the development and function of bone marrowderived macrophages as antigen-presenting cells in SCID mice with transferred rat T cells and/or bone marrow cells. It has been shown that macrophages support the regeneration of the central and peripheral nervous system [50,51]; the cells secrete Interleukin-1 (IL-1) [52] and mediate the release of nerve growth factor (NGF) in a variety of cells such as Schwann cells [53-55]. NGF leads to increased neural survival and regeneration [55-57] and is involved in age-related neuro-degeneration diseases such as Alzheimer's disease [56,58]. Komeda et al. [59] indicated that the blockage of IL-1 activity in the cochlea induces SG degeneration.

Therefore, it is conceivable that when immune functions are preserved under clean environments, $\mathrm{T}$ cells improve the neuro-degeneration system in the inner ear, thereby delaying both accelerated degeneration of the SG cells and age-related SHL in SAMP1 mice (Figure 1).

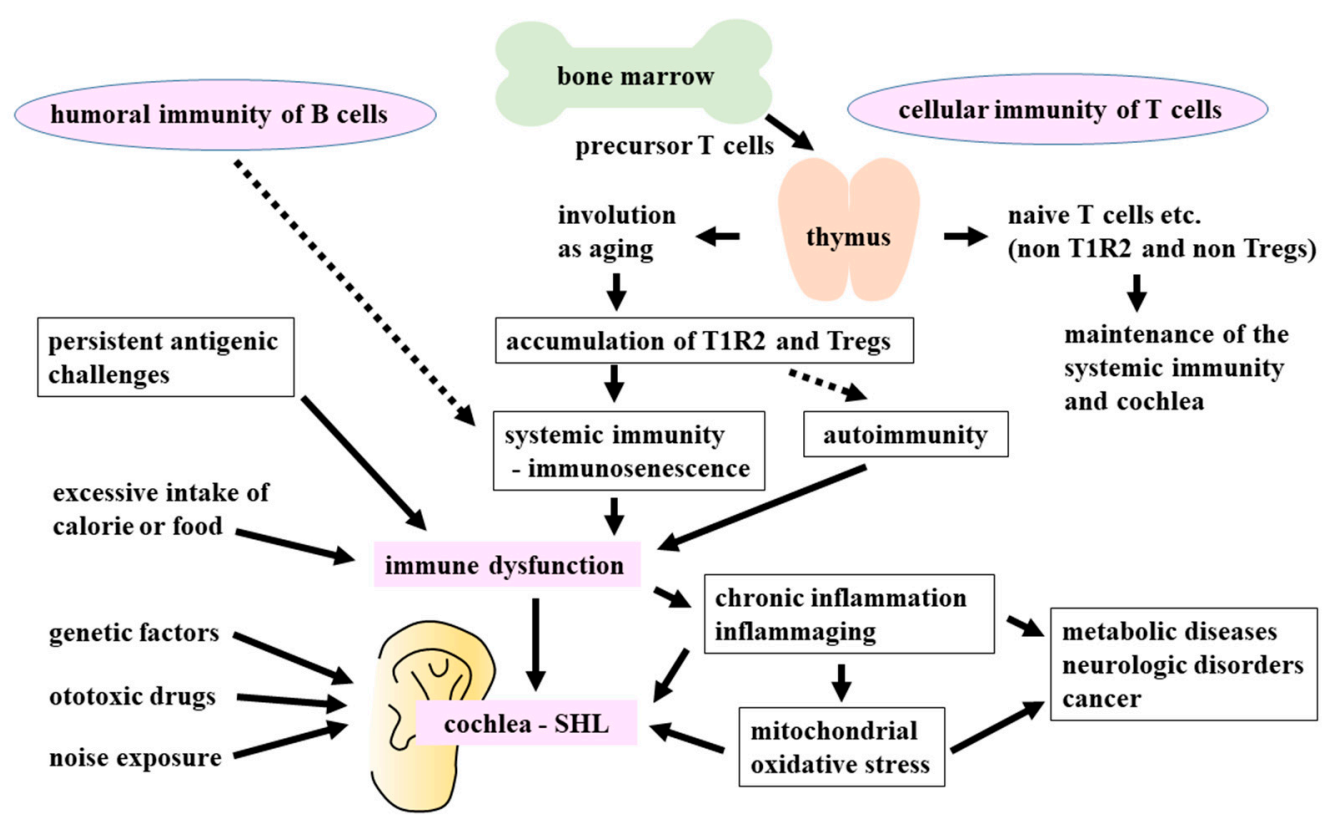

\section{Prevention of age-related SHL by immune rejuvenation}

The profound atrophy of thyme tissue is central to immunosenescence [60] and leads to perturbed output of new T cells extended from hematopoietic stem cells (HSCs), as well as lymphoid progenitors and increased memory lymphocytes with accumulation of dysfunctional senescent cells [61-64].

Age-associated immunodeficiency and cognitive deterioration are two predominant features of the aging process. Disordered immune reactions are closely related to brain impairments including Alzheimer's disease, resulting in the deterioration of central cognitive functions [65-67]. It is widely accepted that immune surveillance of the CNS occurs, and that immune and inflammatory responses 
can take place in the brain, including neurons, by infiltration of circulating immune cells and activation of resident cells [68]. Thymectomy induces an imbalance between lymphocytes, macrophages, and cytokines, which induces neurotransmitter and neuroendocrine changes, and subsequent memory disturbance [69]. The inner ear is also regulated by systemic immunocompetent cells, including T cells and macrophages, which are supplied through the blood-inner ear barrier, similar to the blood-brain barrier [11,70], and these are associated with local inflammation and restoration [40,41,71].

We have previously demonstrated that age-related SHL is prevented in SAMP1 by rejuvenation of recipient immunity by syngeneic inoculation of $\mathrm{CD}^{+} \mathrm{T}$ cells from young donors, while the inoculation of $\mathrm{CD} 8^{+} \mathrm{T}$ cells or $\mathrm{B}$ cells had no preventive effect on age-related SHL [17].

Because rejuvenation of the thymus leads to reconstitution of cellular immunity with function as good as young cells and better than those of aged mice and humans [69], we grafted syngeneic fetal thymi to SAMP1 recipients. Results indicated that the populations of interleukin 1 receptor type II (IL-1R2)-positive T cells (T1R2) and naturally occurring regulatory T cells (nTregs) in CD4 ${ }^{+} \mathrm{T}$ cells increased with aging and that the grafts led to down regulation of T1R2 and nTregs in CD4 ${ }^{+} \mathrm{T}$ cells, reducing the population, age-related SHL, and degeneration of SG in SAMP1 mice [17,18] (Figure 1). Inoculation of $\mathrm{CD}^{+} \mathrm{T}$ cells by deleting T1R2 and nTreg also had the same effects on age-related SHL and SG (manuscript in preparation).

Interleukin (IL)-1 has been particularly implicated in neurodegeneration [68] and is controlled mainly by interleukin-1 receptor type 1 (IL-1R1) to transduce signals, especially IL-1 $\beta$ and interleukin 1 receptor type 2 (IL-1R2), to diminish IL-1 without any transduction of IL-1 binding signals $[52,68]$. IL-1 receptors interact with IL-1 to modulate the functions of leukocytes including $\mathrm{CD} 4^{+} \mathrm{T}$ cells, all cell types of the brain [52], and spiral ganglion (SG) neurons [59]. nTregs accumulate with advanced age, despite thyme involution, leading to a dwindling thyme T-cell population and inducible regulatory $\mathrm{T}$ cells (iTregs), and promoting tissue degeneration and senescence-associated inflammation, as well as disturbances in immune activation against tumors and pathogens [72]. Depletion of Tregs was shown to significantly improve neural survival after mechanical injury in an animal model [73].

\section{Clinical tactics to prevent SHL by immune alteration}

It is not feasible to renew the immune system in autoimmune SHL patients with BMT because of the stressful treatment. Caloric restriction, which limits eating habits, may be impractical or impair the quality of life for people, especially in industrialized countries. On the other hand, current findings suggest at least three immunological strategies to prevent age-related SHL: i) A clean living environment with few pathogens causing inflammation may maintain recipient immunity and cochlear function. ii) Elimination of $\mathrm{T} 1 \mathrm{R} 2$ and $\mathrm{nTreg}$ from $\mathrm{CD}^{+} \mathrm{T}$ cells with antibodies may contribute to immune rejuvenation and prevention of neurosenescence in the cochleas recipients. iii) Use thyme epithelial cells differentiated from autologous pluripotent stem cells [74] or iPS cells. Grafting of these 
cells may lead to immune rejuvenation and prevention of age-related SHL as an anti-aging activity. This is a major objective and the center of much research attention globally. Further studies must be promptly performed to develop this concept in industrialized countries facing expansions in their elderly populations.

\section{Conclusions}

Although Age-related SHL is rapidly increasing in incidence, affecting about half of the population over 75 years old [37], no strategy has been developed for the prevention and treatment of this neurodegenerative disease.

This chronic deterioration progressing in later life is often influenced by systemic immune disturbances, including autoimmunity, chronic inflammation, and immunosenescence. Alteration of systemic immunity by fewer challenges from microbial antigens in the living environment, elimination of immune suppressive lymphocytes like T1R2 and nTregs or immune rejuvenation with reconstituted thymi may contribute not only to renew the cochlear function in SHL, but also to extend a healthy life with functional organs in a vigorous and youthful body, one of humanity's greatest dreams.

\section{Competing Interests}

The authors declare that they have no competing interests.

\section{Authors' contributions}

HI: Study design and writing the manuscript. MI: critical reading and discussion of the manuscript. Both authors have read and approved the final manuscript.

\section{Acknowledgements}

This study was supported by grants-in-aid for scientific research $(08671994,11671712,18591895$, 21592170, and 16K11202) from the Ministry of Education, Science and Culture, a grant from the Millennium program of the Ministry of Education, Culture, Sports, Science and Technology, a grant from the Science Frontier program of the Ministry of Education, Culture, Sports, Science and Technology, a grant from the 21st Century Center of Excellence (COE) program of the Ministry of Education, Culture, Sports, Science and Technology, the Katano and the Shiozaki Yasuko prizes of Kansai Medical University and funding from the Academic Society for Research in Otolaryngology, Kansai Medical University in Japan.

\section{References}

1. Iino, Y.; Usubuchi, H.; Kodama, K.; Takizawa, K.; Kanazawa, T.; Ohta, Y. Bone conduction hearing level in patients with eosinophilic otitis media associated with bronchial asthma. Otol 
Neurotol 2008, 29, 949-952, doi:10.1097/MAO.0b013e318185fb0d.

2. Wierzbicka, M.; Szyfter, W.; Puszczewicz, M.; Borucki, L.; Bartochowska, A. Otologic symptoms as initial manifestation of wegener granulomatosis: diagnostic dilemma. Otol Neurotol 2011, 32, 996-1000, doi:10.1097/MAO.0b013e31822558fd.

3. Bainbridge, K.E.; Hoffman, H.J.; Cowie, C.C. Diabetes and hearing impairment in the United States: audiometric evidence from the National Health and Nutrition Examination Survey, 1999 to 2004. Ann Intern Med 2008, 149, 1-10.

4. Tan, H.E.; Lan, N.S.R.; Knuiman, M.W.; Divitini, M.L.; Swanepoel, D.W.; Hunter, M.; Brennan-Jones, C.G.; Hung, J.; Eikelboom, R.H.; Santa Maria, P.L. Associations between cardiovascular disease and its risk factors with hearing loss-A cross-sectional analysis. Clin Otolaryngol 2018, 43, 172-181, doi:10.1111/coa.12936.

5. Rahne, T.; Clauß, F.; Plontke, S.K.; Keyßer, G. Prevalence of hearing impairment in patients with rheumatoid arthritis, granulomatosis with polyangiitis (GPA, Wegener's granulomatosis), or systemic lupus erythematosus. Clin Rheumatol 2017, 36, 1501-1510, doi:10.1007/s10067017-3651-4.

6. Someya, S.; Xu, J.; Kondo, K.; Ding, D.; Salvi, R.J.; Yamasoba, T.; Rabinovitch, P.S.; Weindruch, R.; Leeuwenburgh, C.; Tanokura, M., et al. Age-related hearing loss in C57BL/6J mice is mediated by Bak-dependent mitochondrial apoptosis. Proc Natl Acad Sci U S A 2009, 106, 19432-19437, doi:10.1073/pnas.0908786106.

7. Someya, S.; Tanokura, M.; Weindruch, R.; Prolla, T.A.; Yamasoba, T. Effects of caloric restriction on age-related hearing loss in rodents and rhesus monkeys. Curr Aging Sci 2010, $3,20-25$.

8. Han, C.; Ding, D.; Lopez, M.C.; Manohar, S.; Zhang, Y.; Kim, M.J.; Park, H.J.; White, K.; Kim, Y.H.; Linser, P., et al. Effects of Long-Term Exercise on Age-Related Hearing Loss in Mice. J Neurosci 2016, 36, 11308-11319, doi:10.1523/JNEUROSCI.2493-16.2016.

9. Fetoni, A.R.; Picciotti, P.M.; Paludetti, G.; Troiani, D. Pathogenesis of presbycusis in animal models: a review. Exp Gerontol 2011, 46, 413-425, doi:10.1016/j.exger.2010.12.003.

10. Iwai, H.; Fernandes, G. Immunological functions in food-restricted rats: enhanced expression of high-affinity interleukin-2 receptors on splenic T cells. Immunol Lett 1989, 23, 125-132.

11. Iwai, H.; Tomoda, K.; Sugiura, K.; Inaba, M.; Ikehara, S.; Yamashita, T. T cells infiltrating from the systemic circulation proliferate in the endolymphatic sac. Ann Otol Rhinol Laryngol 1999, 108, 1146-1150, doi:10.1177/000348949910801209.

12. Lee, S.; Iwai, H.; Sugiura, K.; Takeuchi, K.; Kushida, T.; Tomoda, K.; Inaba, M.; Yamashita, T.; Ikehara, S. Prevention of autoimmune hearing loss in MRL/lpr mice by bone marrow transplantation. Bone Marrow Transplant 2000, 26, 887-892, doi:10.1038/sj.bmt.1702636.

13. Iwai, H.; Lee, S.; Inaba, M.; Baba, S.; Yamashita, T.; Ikehara, S. Bone marrow transplantation 
as a strategy for the treatment of autoimmune hearing loss in MRL/Mp-lpr/lpr mice. $J$ Neuroimmunol 2005, 168, 76-82, doi:10.1016/j.jneuroim.2005.07.020.

14. Iwai, H.; Lee, S.; Inaba, M.; Sugiura, K.; Tomoda, K.; Yamashita, T.; Ikehara, S. Prevention of accelerated presbycusis by bone marrow transplantation in senescence-accelerated mice. Bone Marrow Transplant 2001, 28, 323-328, doi:10.1038/sj.bmt.1703152.

15. Iwai, H.; Lee, S.; Inaba, M.; Sugiura, K.; Baba, S.; Tomoda, K.; Yamashita, T.; Ikehara, S. Correlation between accelerated presbycusis and decreased immune functions. Exp Gerontol 2003, 38, 319-325.

16. Iwai, H.; Baba, S.; Omae, M.; Lee, S.; Yamashita, T.; Ikehara, S. Maintenance of systemic immune functions prevents accelerated presbycusis. Brain Res 2008, 1208, 8-16, doi:10.1016/j.brainres.2008.02.069.

17. Iwai, H.; Inaba, M. Fetal thymus graft prevents age-related hearing loss and up regulation of the IL-1 receptor type II gene in CD4(+) T cells. J Neuroimmunol 2012, 250, 1-8, doi:10.1016/j.jneuroim.2012.05.007.

18. Iwai, H.; Inaba, M. Fetal thymus graft enables recovery from age-related hearing loss and expansion of CD4-Positive T cells expressing IL-1 receptor type 2 and regulatory T Cells. Immun Ageing 2015, 12, 26, doi:10.1186/s12979-015-0053-9.

19. Krance, R.; Brenner, M. BMT beats autoimmune disease. Nat Med 1998, 4, 153-155.

20. Burt, R.K.; Traynor, A.E.; Craig, R.; Marmont, A.M. The promise of hematopoietic stem cell transplantation for autoimmune diseases. Bone Marrow Transplant 2003, 31, 521-524, doi:10.1038/sj.bmt.1703868.

21. Fassas, A.; Passweg, J.R.; Anagnostopoulos, A.; Kazis, A.; Kozak, T.; Havrdova, E.; Carreras, E.; Graus, F.; Kashyap, A.; Openshaw, H., et al. Hematopoietic stem cell transplantation for multiple sclerosis. A retrospective multicenter study. J Neurol 2002, 249, 1088-1097, doi:10.1007/s00415-002-0800-7.

22. Ruckenstein, M.J.; Keithley, E.M.; Bennett, T.; Powell, H.C.; Baird, S.; Harris, J.P. Ultrastructural pathology in the stria vascularis of the MRL-Fasl(lpr) mouse. Hear Res 1999, 131, 22-28.

23. Kusakari, C.; Hozawa, K.; Koike, S.; Kyogoku, M.; Takasaka, T. MRL/MP-lpr/lpr mouse as a model of immune-induced sensorineural hearing loss. Ann Otol Rhinol Laryngol Suppl 1992, $157,82-86$.

24. Theofilopoulos, A.N.; Kofler, R.; Singer, P.A.; Dixon, F.J. Molecular genetics of murine lupus models. Adv Immunol 1989, 46, 61-109.

25. Kaylie, D.M.; Hefeneider, S.H.; Kempton, J.B.; Siess, D.C.; Vedder, C.T.; Merkens, L.S.; Trune, D.R. Decreased cochlear DNA receptor staining in MRL.MpJ-Fas(lpr) autoimmune mice with hearing loss. Laryngoscope 2001, 111, 1275-1280, doi:10.1097/00005537- 
200107000-00025.

26. Lin, D.W.; Trune, D.R. Breakdown of stria vascularis blood-labyrinth barrier in $\mathrm{C} 3 \mathrm{H} / \mathrm{lpr}$ autoimmune disease mice. Otolaryngol Head Neck Surg 1997, 117, 530-534, doi:10.1016/S0194-59989770026-3.

27. Trune, D.R. Cochlear immunoglobulin in the $\mathrm{C} 3 \mathrm{H} / \mathrm{lpr}$ mouse model for autoimmune hearing loss. Otolaryngol Head Neck Surg 1997, 117, 504-508, doi:10.1016/S0194-59989770022-6.

28. Reiter, D.; Konkle, D.F.; Myers, A.R.; Schimmer, B.; Sugar, J.O. Middle ear immittance in rheumatoid arthritis. Arch Otolaryngol 1980, 106, 114-117.

29. Elwany, S.; el Garf, A.; Kamel, T. Hearing and middle ear function in rheumatoid arthritis. $J$ Rheumatol 1986, 13, 878-881.

30. Kastanioudakis, I.; Skevas, A.; Danielidis, V.; Tsiakou, E.; Drosos, A.A.; Moustopoulos, M.H. Inner ear involvement in rheumatoid arthritis: a prospective clinical study. J Laryngol Otol 1995, 109, 713-718.

31. Jacob, A.; Ledingham, J.G.; Kerr, A.I.; Ford, M.J. Ulcerative colitis and giant cell arteritis associated with sensorineural deafness. J Laryngol Otol 1990, 104, 889-890.

32. Kumar, B.N.; Walsh, R.M.; Wilson, P.S.; Carlin, W.V. Sensorineural hearing loss and ulcerative colitis. J Laryngol Otol 1997, 111, 277-278.

33. Cody, D.T.; Sones, D.A. Relapsing polychondritis: audiovestibular manifestations. Laryngoscope 1971, 81, 1208-1222, doi:10.1288/00005537-197108000-00004.

34. Kanzaki, J.; Ouchi, T. Steroid-responsive bilateral sensorineural hearing loss and immune complexes. Arch Otorhinolaryngol 1981, 230, 5-9.

35. Yamasoba, T.; Lin, F.R.; Someya, S.; Kashio, A.; Sakamoto, T.; Kondo, K. Current concepts in age-related hearing loss: epidemiology and mechanistic pathways. Hear Res 2013, 303, 30-38, doi:10.1016/j.heares.2013.01.021.

36. Hosokawa, M. A higher oxidative status accelerates senescence and aggravates agedependent disorders in SAMP strains of mice. Mech Ageing Dev 2002, 123, 1553-1561.

37. Gates, G.A.; Mills, J.H. Presbycusis. Lancet 2005, 366, 1111-1120, doi:10.1016/S01406736(05)67423-5.

38. Verschuur, C.; Agyemang-Prempeh, A.; Newman, T.A. Inflammation is associated with a worsening of presbycusis: evidence from the MRC national study of hearing. Int $J$ Audiol 2014, 53, 469-475, doi:10.3109/14992027.2014.891057.

39. Accardi, G.; Caruso, C. Immune-inflammatory responses in the elderly: an update. Immun Ageing 2018, 15, 11, doi:10.1186/s12979-018-0117-8.

40. Cserr, H.F.; Knopf, P.M. Cervical lymphatics, the blood-brain barrier and the immunoreactivity of the brain: a new view. Immunol Today 1992, 13, 507-512, doi:10.1016/0167-5699(92)90027-5. 
41. Hashimoto, S.; Billings, P.; Harris, J.P.; Firestein, G.S.; Keithley, E.M. Innate immunity contributes to cochlear adaptive immune responses. Audiol Neurootol 2005, 10, 35-43, doi:10.1159/000082306.

42. Frisina, S.T.; Mapes, F.; Kim, S.; Frisina, D.R.; Frisina, R.D. Characterization of hearing loss in aged type II diabetics. Hear Res 2006, 211, 103-113, doi:10.1016/j.heares.2005.09.002.

43. Gates, G.A.; Cobb, J.L.; D'Agostino, R.B.; Wolf, P.A. The relation of hearing in the elderly to the presence of cardiovascular disease and cardiovascular risk factors. Arch Otolaryngol Head Neck Surg 1993, 119, 156-161.

44. Hosono, M.; Hanada, K.; Toichi, E.; Naiki, H.; Higuchi, K.; Hosokawa, T. Immune abnormality in relation to nonimmune diseases in SAM mice. Exp Gerontol 1997, 32, 181195.

45. Flood, J.F.; Morley, J.E. Early onset of age-related impairment of aversive and appetitive learning in the SAM-P/8 mouse. J Gerontol 1992, 47, B52-59.

46. Saitoh, Y.; Hosokawa, M.; Shimada, A.; Watanabe, Y.; Yasuda, N.; Takeda, T.; Murakami, Y. Age-related hearing impairment in senescence-accelerated mouse (SAM). Hear Res 1994, 75, 27-37.

47. Liu, B.; Kimura, Y. Local immune response to respiratory syncytial virus infection is diminished in senescence-accelerated mice. $J$ Gen Virol 2007, 88, 2552-2558, doi:10.1099/vir.0.83089-0.

48. Uttara, B.; Singh, A.V.; Zamboni, P.; Mahajan, R.T. Oxidative stress and neurodegenerative diseases: a review of upstream and downstream antioxidant therapeutic options. Curr Neuropharmacol 2009, 7, 65-74, doi:10.2174/157015909787602823.

49. Subramanian, S.; Bourdette, D.N.; Corless, C.; Vandenbark, A.A.; Offner, H.; Jones, R.E. T lymphocytes promote the development of bone marrow-derived APC in the central nervous system. J Immunol 2001, 166, 370-376.

50. Lazarov-Spiegler, O.; Solomon, A.S.; Zeev-Brann, A.B.; Hirschberg, D.L.; Lavie, V.; Schwartz, M. Transplantation of activated macrophages overcomes central nervous system regrowth failure. FASEB $J \mathbf{1 9 9 6}, 10,1296-1302$.

51. David, S.; Bouchard, C.; Tsatas, O.; Giftochristos, N. Macrophages can modify the nonpermissive nature of the adult mammalian central nervous system. Neuron 1990, 5, 463469.

52. Dinarello, C.A. Biologic basis for interleukin-1 in disease. Blood 1996, 87, 2095-2147.

53. Hahn, M.; Lorez, H.; Fischer, G. Effect of calcitriol in combination with corticosterone, interleukin-1beta, and transforming growth factor-betal on nerve growth factor secretion in an astroglial cell line. J Neurochem 1997, 69, 102-109.

54. Saporito, M.S.; Wilcox, H.M.; Hartpence, K.C.; Lewis, M.E.; Vaught, J.L.; Carswell, S. 
Pharmacological induction of nerve growth factor mRNA in adult rat brain. Exp Neurol 1993, 123, 295-302, doi:10.1006/exnr.1993.1162.

55. Fagan, A.M.; Gage, F.H. Cholinergic sprouting in the hippocampus: a proposed role for IL1. Exp Neurol 1990, 110, 105-120.

56. Capsoni, S.; Ugolini, G.; Comparini, A.; Ruberti, F.; Berardi, N.; Cattaneo, A. Alzheimerlike neurodegeneration in aged antinerve growth factor transgenic mice. Proc Natl Acad Sci U S A 2000, 97, 6826-6831.

57. Thoenen, H.; Bandtlow, C.; Heumann, R. The physiological function of nerve growth factor in the central nervous system: comparison with the periphery. Rev Physiol Biochem Pharmacol 1987, 109, 145-178.

58. Connor, B.; Dragunow, M. The role of neuronal growth factors in neurodegenerative disorders of the human brain. Brain Res Brain Res Rev 1998, 27, 1-39.

59. Komeda, M.; Roessler, B.J.; Raphael, Y. The influence of interleukin-1 receptor antagonist transgene on spiral ganglion neurons. Hear Res 1999, 131, 1-10.

60. Chidgey, A.; Dudakov, J.; Seach, N.; Boyd, R. Impact of niche aging on thymic regeneration and immune reconstitution. Semin Immunol 2007, 19, 331-340, doi:10.1016/j.smim.2007.10.006.

61. Linton, P.J.; Dorshkind, K. Age-related changes in lymphocyte development and function. Nat Immunol 2004, 5, 133-139, doi:10.1038/ni1033.

62. DelaRosa, O.; Pawelec, G.; Peralbo, E.; Wikby, A.; Mariani, E.; Mocchegiani, E.; Tarazona, R.; Solana, R. Immunological biomarkers of ageing in man: changes in both innate and adaptive immunity are associated with health and longevity. Biogerontology 2006, 7, 471481, doi:10.1007/s10522-006-9062-6.

63. Wistuba-Hamprecht, K.; Haehnel, K.; Janssen, N.; Demuth, I.; Pawelec, G. Peripheral blood T-cell signatures from high-resolution immune phenotyping of $\gamma \delta$ and $\alpha \beta$ T-cells in younger and older subjects in the Berlin Aging Study II. Immun Ageing 2015, 12, 25, doi:10.1186/s12979-015-0052-x.

64. Pawelec, G. Hallmarks of human "immunosenescence": adaptation or dysregulation? Immun Ageing 2012, 9, 15, doi:10.1186/1742-4933-9-15.

65. McGeer, P.L.; Rogers, J.; McGeer, E.G. Neuroimmune mechanisms in Alzheimer disease pathogenesis. Alzheimer Dis Assoc Disord 1994, 8, 149-158.

66. Licastro, F.; Candore, G.; Lio, D.; Porcellini, E.; Colonna-Romano, G.; Franceschi, C.; Caruso, C. Innate immunity and inflammation in ageing: a key for understanding age-related diseases. Immun Ageing 2005, 2, 8, doi:10.1186/1742-4933-2-8.

67. Perry, V.H. Contribution of systemic inflammation to chronic neurodegeneration. Acta Neuropathol 2010, 120, 277-286, doi:10.1007/s00401-010-0722-x. 
68. Allan, S.M.; Tyrrell, P.J.; Rothwell, N.J. Interleukin-1 and neuronal injury. Nat Rev Immunol 2005, 5, 629-640, doi:10.1038/nri1664.

69. Song, C. The effect of thymectomy and IL-1 on memory: implications for the relationship between immunity and depression. Brain Behav Immun 2002, 16, 557-568.

70. Juhn, S.K.; Rybak, L.P.; Prado, S. Nature of blood-labyrinth barrier in experimental conditions. Ann Otol Rhinol Laryngol 1981, 90, 135-141, doi:10.1177/000348948109000208.

71. Bhave, S.A.; Oesterle, E.C.; Coltrera, M.D. Macrophage and microglia-like cells in the avian inner ear. J Comp Neurol 1998, 398, 241-256.

72. Jagger, A.; Shimojima, Y.; Goronzy, J.J.; Weyand, C.M. Regulatory T cells and the immune aging process: a mini-review. Gerontology 2014, 60, 130-137, doi:10.1159/000355303.

73. Kipnis, J.; Avidan, H.; Caspi, R.R.; Schwartz, M. Dual effect of CD4+CD25+ regulatory T cells in neurodegeneration: a dialogue with microglia. Proc Natl Acad Sci U S A 2004, 101 Suppl 2, 14663-14669, doi:10.1073/pnas.0404842101.

74. Inami, Y.; Yoshikai, T.; Ito, S.; Nishio, N.; Suzuki, H.; Sakurai, H.; Isobe, K. Differentiation of induced pluripotent stem cells to thymic epithelial cells by phenotype. Immunol Cell Biol 2011, 89, 314-321, doi:10.1038/icb.2010.96.

\section{Figure legend}

Figure 1. SHL and immune dysfunction 